\title{
Hydrogen storage - status and prospects
}

\section{E. MacA. Gray*}

\begin{abstract}
More than three decades of research have not solved the problem of storing hydrogen on board for transport fuel. Hydrogen storage therefore constitutes a major technological barrier to the hydrogen economy. The present paper considers why the problem is so tough and assesses the prospects for the two most popular storage concepts, pressurised gas storage systems and condensed materials, exemplified by lithium based complexes. It is concluded that efforts to achieve 'condensed matter' hydrogen storage are showing promise and are still vitally important because pressurised gas storage for automobiles is very unlikely to meet the targets for energy density set by the US Department of Energy.
\end{abstract}

Keywords: Hydrogen storage, Pressurised tank, Metal hydride, Lithium

\section{Introduction}

Research into hydrogen storage for automotive transport has been galvanised twice: first by the oil shocks of the 1970s and again in the past several years by concerns over security of energy supply. The latter concerns led to the announcement by US President George Bush in January 2003 of the project to build the hydrogen powered freedom car, to be available by 2020 .

The years between these events saw the development and maturation of the nickel-metal-hydride battery, but the 1970s goal of a storage bed for gaseous hydrogen with sufficient energy densities by mass and volume to engage automotive manufacturers has proved elusive.

Early hopes rested on metal hydrides, in which (in favourable cases) hydrogen is stored in solid form at just a few bar pressure and can be retrieved by heating to a few tens of kelvin above room temperature. Storage occurs by the dissociation of the hydrogen molecule at the material surface and diffusion of hydrogen atoms to interstitial sites in the metal lattice. The most fundamental technological problem was and is the mass of the host atoms. While very many alloys, intermetallics and pure metals absorb interstitial hydrogen at atomic ratios of 1,2 or even $3 \mathrm{H}$ per host atom, leading to very high stored energy density by volume, the mass energy density achieved is insufficient for practical automotive storage, except for the lightest hosts. The iconic intermetallic $\mathrm{LaNi}_{5}$ desorbs hydrogen at pressures of a few bars near room temperature with rapid kinetics, but it reversibly stores only 1.4 mass $\%$ hydrogen, ignoring the mass of the containment system, which must include allowances for pressure containment and both mass $\left(\mathrm{H}_{2}\right)$ and heat transfer (enthalpy of absorption and desorption, $\sim 30 \mathrm{~kJ} \mathrm{~mol}^{-1} \mathrm{H}_{2}$ for $\mathrm{LaNi}_{5}-\mathrm{H}_{2}$ ) within the storage bed. The metal with highest reversible capacity, at $7 \cdot 7 \mathrm{mass} \%$, is $\mathrm{Mg}$, but $\mathrm{MgH}_{2}$ requires temperatures

Nanoscale Science and Technology Centre, Griffith University, Nathan 4111, Australia

*Corresponding author, email E.Gray@griffith.edu.au above $300^{\circ} \mathrm{C}$ for release of hydrogen at 1 bar, and the kinetics of desorption and reabsorption are very slow. Other metal hydrides, e.g. $\mathrm{AlH}_{3}(10 \cdot 1 \mathrm{mass} \%)$ and $\mathrm{LiH}$ $\left(12.7 \mathrm{mass}^{\%} \%\right)$ are less metallic in character and even more stable than $\mathrm{MgH}_{2}$.

By the 1990s other hydrogen fueling modalities were being actively considered, and the current generation of hydrogen powered transport, particularly passenger buses, runs almost exclusively on hydrogen stored in tanks pressurised to 350-700 bar.

The purpose of the present paper is not to comprehensively introduce and review hydrogen storage research, for which the reader is referred to the paper by Schlapbach and Züttel. ${ }^{1}$ Its aim is to consider the current status of and prospects for hydrogen storage relative to the US Department of Energy (DOE) targets for hydrogen storage, in order to assess the likelihood of a practical storage system being realised within the stipulated time frame, or indeed at all. The focus is on direct refueling with hydrogen gas, so liquid state or 'chemical' storage of hydrogen, in which a hydrogen containing fuel is exchanged at the refueling station (gasoline or methanol, for example), rather than hydrogen gas, will not be considered in detail. After outlining the nature of the hydrogen storage problem, the first consideration of the present work is whether pressurised gas technology can meet these targets, based on a fairly realistic model which accounts for the strength and density of the material from which the pressure vessel is constructed. Then a brief review is made of some of the new generation lithium based candidate materials for solid state storage which have emerged since the 2001 review by Schlapbach and Züttel. ${ }^{1}$ These comparisons will be visualised using a diagrammatic representation introduced by Schlapbach and Züttel. ${ }^{1}$

\section{Hydrogen storage problem}

Table 1 summarises the fundamental problem with hydrogen storage for automotive use: the automotive industry has developed based on the very high energy density of gasoline, with which hydrogen is 
uncompetitive except in pure form - gasoline has $\sim 17$ mass $\%$ hydrogen, but bonded to carbon, with a higher bond energy than the $\mathrm{H}-\mathrm{H}$ bond.

Thus to match the energy densities by mass and by volume of gasoline, a hydrogen fuel tank would need to store $\sim 35$ mass $\%$ hydrogen at four times liquid density! The US DOE has established energy density targets, ${ }^{2}$ reproduced in Table 2 .

The 2005 targets were not met. Although the 2015 targets are presently out of reach, they are very modest compared with the energy densities of gasoline, emphasising the difficulty of the problem faced. The premise of the DOE targets is that automotive manufacturers will accept any hydrogen storage technology that meets them as worthy of serious consideration for incorporation in fully commercialised vehicles.

\section{Pressurised gas hydrogen storage}

In 2006 the state of the art hydrogen storage system is a 700 bar pressurised tank, based on sophisticated engineering design with low density composite materials that derive high tensile strength from carbon fibres. It is instructive to consider on a simple model that materials properties would be required to push this technology to meet the DOE targets for energy density by mass and volume.

Figure 1 shows a model cylindrical pressure vessel with hemispherical end caps. For simplicity it is assumed that the actual materials of construction may be represented by composite values of strength and density. Ignoring any access port(s), the pressure limitation is set by the wall thickness of the cylinder relative to its radius.

For a given design pressure $p_{\text {des }}$ and design tensile strength $f_{\text {des }}$ the required wall thickness is given by

$$
t=R\left(K^{1 / 2}-1\right)
$$

where

$$
K=\frac{f_{\text {des }}+p_{\text {des }}}{f_{\text {des }}-p_{\text {des }}}
$$

Depending on local regulations, $p_{\text {des }}$ may be the same as the working pressure or slightly higher. The value of $f_{\text {des }}$

Table 1 Comparison of energy densities of pure hydrogen and gasoline

\begin{tabular}{lll}
\hline Hydrogen & $\begin{array}{l}\text { Mass energy } \\
\text { density, } \mathbf{~ J ~ k g ~}^{-1}\end{array}$ & $\begin{array}{l}\text { Volume energy } \\
\text { density }\end{array}$ \\
\hline & & $3 \mathrm{~mJ} \mathrm{~kg}^{-1}$ (350 bar) \\
Pure hydrogen & 120 & $8 \mathrm{~mJ} \mathrm{~L}^{-1}$ (liquid) \\
Gasoline & 44 & $32 \mathrm{~mJ} \mathrm{~L}^{-1}$ \\
\hline
\end{tabular}

Table 2 US DOE targets for energy density in a viable

\begin{tabular}{|c|c|c|}
\hline $\begin{array}{l}\text { DOE } \\
\text { target for }\end{array}$ & $\begin{array}{l}\text { Mass energy density } \\
\mathrm{mJ} \mathrm{kg}^{-1}\left(\mathrm{~kW} \mathrm{~h} \mathrm{~kg}^{-1}\right)\end{array}$ & 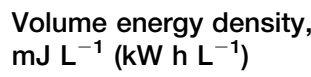 \\
\hline 2005 & $\begin{array}{l}5 \cdot 4 \\
(1 \cdot 5)\end{array}$ & $\begin{array}{l}4 \cdot 3 \\
(1 \cdot 2)\end{array}$ \\
\hline 2010 & $\begin{array}{l}7 \cdot 2 \\
(2 \cdot 0)\end{array}$ & $\begin{array}{l}5 \cdot 4 \\
(1 \cdot 5)\end{array}$ \\
\hline 2015 & $\begin{array}{l}10 \cdot 8 \\
(3 \cdot 0)\end{array}$ & $\begin{array}{l}9 \cdot 7 \\
(2 \cdot 7)\end{array}$ \\
\hline
\end{tabular}
hydrogen storage system*

*The targets include the mass and volume of the container.

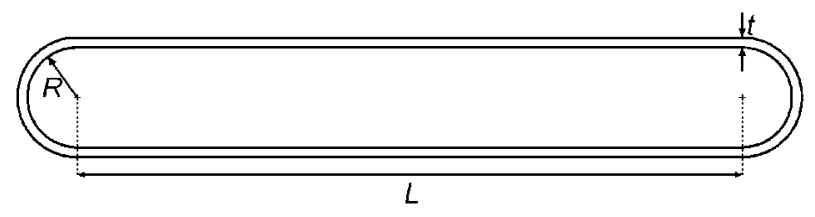

1 Model pressurised hydrogen storage tank used to construct volume density against mass density curves displayed in Fig. 2

relative to the ultimate tensile strength (UTS) of the material is set by governing authorities. Here it is assumed that

$$
\frac{U T S}{f_{\text {des }}}=2 \cdot 35
$$

Conveniently referring the calculations to $1 \mathrm{~m}^{3}$ of $\mathrm{H}_{2}$, the required parameters are easily calculated

$$
\begin{aligned}
& m_{\mathrm{H}_{2}}=\frac{p_{\text {des }} M}{Z R T} \\
& m_{\text {cyl }}=\left(V_{\text {cyl }}-1\right) \rho_{\text {cyl }} \\
& V_{\text {cyl }}=\frac{4}{3} \pi R^{3} K^{3 / 2}+\pi R^{2} L K \\
& m a s{ }^{0} \%=\frac{100 m_{\mathrm{H}_{2}}}{m_{\text {cyl }}+m_{\mathrm{H}_{2}}} \\
& \rho_{\text {vol }}=\frac{m_{\mathrm{H}_{2}}}{V_{\text {cyl }}}
\end{aligned}
$$

where $m_{\mathrm{H}_{2}}$ is the mass of hydrogen contained, $M=2.0158 \mathrm{amu}, Z$ is the compressibility of hydrogen, $m_{\text {cyl }}$ is the mass of the pressure vessel, $V_{\text {cyl }}$ is the overall volume of the pressure vessel including the contained hydrogen, $\rho_{\text {cyl }}$ is the density of the material of the pressure vessel, mass $\%$ is the mass density of stored hydrogen including the pressure vessel and $\rho_{\mathrm{vol}}$ is the volume density of stored hydrogen including the pressure vessel. For convenience of calculation it was assumed that

$$
L=\frac{40}{3} R
$$

Figure 2 shows the model results for a number of scenarios, where a material is characterised by its design tensile strength and density. The DOE targets are indicated. The area of the diagram targeted for 2015 is thus the upper right portion.

The three advanced materials selected are:

(i) a hypothetical composite whose material density $\left(1.55 \mathrm{~g} \mathrm{cc}^{-1}\right)$ and design tensile strength $(310 \mathrm{MPa})$ emulate the performance of a state of the art 700 bar pressure tank, achieving 3.9 mass $\%$ and $24 \mathrm{~kg} \mathrm{~m}^{-3}$ (Ref. 3)

(ii) a hypothetical and as yet unrealised composite with the tensile strength and density of pure carbon fibre

(iii) a hypothetical material whose properties are chosen to meet the 2015 DOE density targets for mass and volume.

A conventional pressure vessel made of high strength aluminium is included for comparison, using the design tensile strength mandated for its use in pressure vessels by Standards Australia.

Although its performance is greatly superior to that of the aluminium tank, the state of the art composite tank 


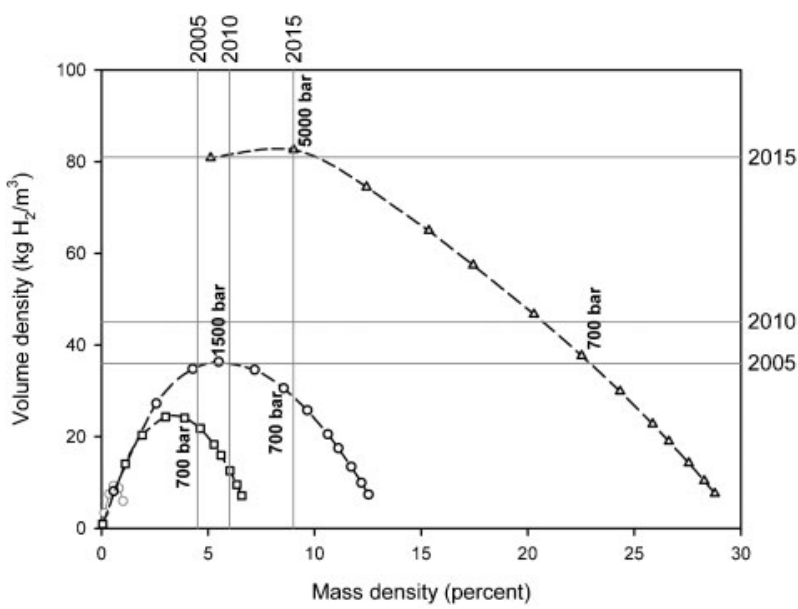

aluminium $5083, f_{\text {des }}=86 \mathrm{MPa}, \rho_{\text {cyl }}=2.70 \mathrm{~g} \mathrm{cc}^{-1}$; : state of art composite material based on carbon fibre, $f_{\text {des }}=310 \mathrm{MPa}, \rho_{\text {cyl }}=1.55 \mathrm{~g} \mathrm{cc}^{-1}$; hypothetical composite with properties of pure carbon fibre, $f_{\text {des }}=600 \mathrm{MPa}$, $\rho_{\text {cyl }}=1.50 \mathrm{~g} \mathrm{cc}^{-1}$; hypothetical material specified to meet 2015 DOE targets, $f_{\text {des }}=4000 \mathrm{MPa}, \rho_{\text {cyl }}=3.60 \mathrm{~g} \mathrm{cc}^{-1}$

2 Comparison of performance of model pressurised hydrogen storage tank for hypothetical materials with design tensile strength $f_{\text {des }}$ and density $\rho_{\text {cyl: }}$ : solid grey lines indicate DOE targets listed in Table 2; design pressure values reading from lower right are in bar: $100,140,200,280,350,500,700,1000,1500,2000$, 3500,5000 and 10000

does not meet even the 2005 DOE targets. In fact the 2005 targets are just met by the non-existent material with the properties of pure carbon fibre, at a hydrogen pressure approaching 1500 bar. The material specified as to its strength and density to meet the 2015 targets is very much in the realm of speculation, being much stronger than carbon fibre. The design pressure for this system would need to approach 5000 bar.

While 350 bar pressurised tanks may find acceptance, it is not at all clear that 700 bar tanks will be accepted by consumers, whatever the reassurances provided through destructive testing. It seems highly improbable that pressurised tanks could ever be constructed to meet the 2010 and 2015 targets and gain consumer acceptance of the tank itself and the kilobar rated refueling system. The fundamental problem here is that, while even more advanced materials may be developed that weigh less and occupy less volume, the lowest pressures that can be applied to store hydrogen gas at room temperature with the required volume density are still very high, even if the tank is ignored altogether. This basic reality is driven home by Table 3 , where the pressure required to achieve a given volume density of hydrogen gas has been calculated by numerically solving the compressibility modified ideal gas law. ${ }^{4,5}$

The author's view is that it is effectively impossible that a pressure vessel meeting the 2015 volume density target will be built and widely commercialised, given

Table 3 Hydrogen pressures required to achieve DOE volume density targets, ignoring container

\begin{tabular}{llr}
\hline DOE target for & $\mathrm{H}_{\mathbf{2}}$ density, $\mathbf{k g ~ m}^{-\mathbf{3}}$ & $\mathrm{H}_{\mathbf{2}}$ pressure, bar \\
\hline 2005 & 36 & 624 \\
2010 & 45 & 892 \\
2015 & 81 & 2550 \\
\hline
\end{tabular}

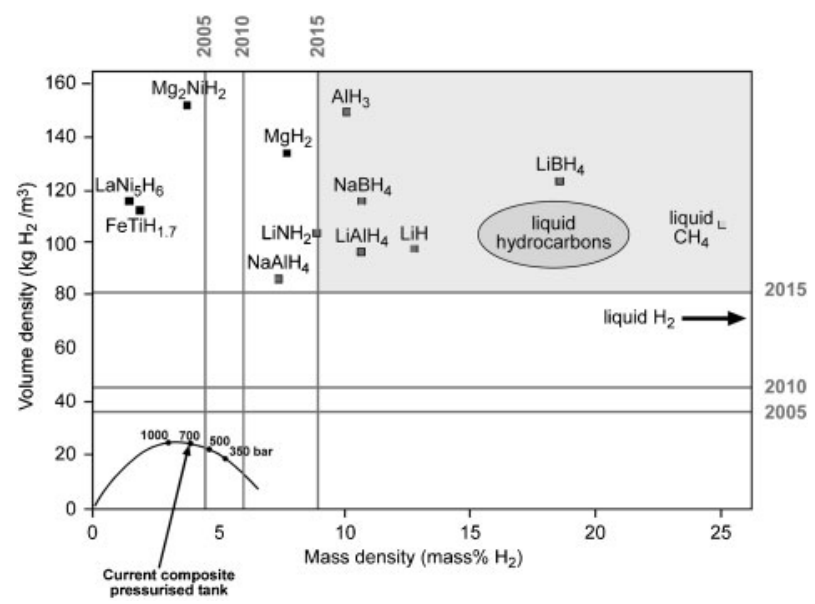

3 Density space for candidate materials for hydrogen storage in condensed matter form: solid grey lines indicate DOE targets listed in Table 2; only those materials in upper right portion of space have chance of meeting 2015 targets; included for comparison is model tank from Fig. 2 representing current achievement of pressurised tank technology; note that densities for condensed storage materials do not include mass and volume of container, as these are less significant owing to relatively low pressure

that the very lowest working pressure would be 2550 bar with an infinitely strong material. Thus, while developments such as materials based on carbon nanotubes (UTS $\approx 130 \mathrm{GPa}$ ) are conceivable, the problem of the hydrogen pressure can only be addressed by cooling the gas or by continuing the efforts to achieve hydrogen storage as condensed matter.

\section{Solid state hydrogen storage}

Figure 3 surveys the volume density - mass density space, based on Ref. 1, with some materials added that have excited interest in the period since 2001 .

The inclusion of the state of the art pressurised tank emphasises the differences between the pressurised gas and 'condensed matter' storage modalities: the volume density of hydrides is excellent, but the hydrides with acceptable mass density for 2015 are non-metallic and relatively intractable owing to strong bonding of $\mathrm{H}$. Storage based on nanostructured carbons is not included in Fig. 3 because the consensus is that a mass density of several mass $\%$ is the upper limit. ${ }^{6}$ Liquid hydrocarbons, including liquid methane, are excellent in terms of density, and liquefied natural gas is already a common fuel in bus fleets, but the basic premise of the hydrogen economy is that carbon containing fuels are to be phased out to eliminate this source of greenhouse gases.

Attention was strongly directed to lithium based materials by the work of Chen et al., ${ }^{7}$ which showed that $\mathrm{Li}_{3} \mathrm{~N}$ absorbs and desorbs hydrogen via

$$
\begin{array}{r}
\mathrm{Li}_{3} \mathrm{~N}+2 \mathrm{H}_{2} \leftrightarrow \mathrm{Li}_{2} \mathrm{NH}+\mathrm{LiH}+\mathrm{H}_{2} \\
\leftrightarrow \mathrm{LiNH}_{2}+2 \mathrm{LiH}
\end{array}
$$

The total amount of hydrogen contained in the reactants is $10 \cdot 4 \mathrm{mass} \%$, each reaction controlling half the total stored $\mathrm{H}$. The amount of $\mathrm{H}$ actually absorbed was $9 \cdot 4 \operatorname{mass} \%$, but the first reaction takes place at an unacceptably low pressure and only the roughly $5 \cdot 2$ mass $\%$ 
of hydrogen stored in $\mathrm{LiNH}_{2}$ could be readily recovered, with a desorption temperature approaching $300^{\circ} \mathrm{C}$ being required to recover most of the $\mathrm{H}(\sim 7 \mathrm{mass} \%)$ at pressures above 1 bar.

Although $\mathrm{LiH}$ would ordinarily be regarded as stable, decomposing above $500^{\circ} \mathrm{C}$, Ichikawa et al. ${ }^{8}$ proposed that ammonia is an intermediary, with the sequence

$$
\begin{aligned}
& \mathrm{LiNH}_{2} \leftrightarrow 0 \cdot 5 \mathrm{Li}_{2} \mathrm{NH}+0 \cdot 5 \mathrm{NH}_{3} \\
& 0 \cdot 5 \mathrm{NH}_{3}+0 \cdot 5 \mathrm{LiH} \leftrightarrow 0 \cdot 5 \mathrm{LiNH}_{2}+0 \cdot 5 \mathrm{H}_{2}
\end{aligned}
$$

repeating until all the $\mathrm{LiNH}_{2}$ is consumed. As there is no ammonia left over, the effect is no ammonia production. This is an important point, as ammonia is a potent polymer electrolyte membrane (PEM) fuel cell poison ${ }^{9}$ and a controversial byproduct in some of the reactions surveyed below.

Nakamori et al. ${ }^{10}$ concluded that $\mathrm{LiNH}_{2}$ would be destabilised by partial substitution of $\mathrm{Li}$ for $\mathrm{Mg}$ and claim that a 4:1 molar ratio of $\mathrm{Li}_{3} \mathrm{~N}$ and $\mathrm{Mg}_{3} \mathrm{~N}_{2}$ reversibly stores $9 \cdot 1 \mathrm{wt} \% \mathrm{H}$ with no $\mathrm{NH}_{3}$ production, according to

$$
3 \mathrm{Mg}\left(\mathrm{NH}_{2}\right)_{2}+12 \mathrm{LiH} \leftrightarrow 4 \mathrm{Li}_{3} \mathrm{~N}+\mathrm{Mg}_{3} \mathrm{~N}_{2}+12 \mathrm{H}_{2}
$$

The reactants were formed by heating mixtures of $\mathrm{Li}_{3} \mathrm{~N}$ and $\mathrm{Mg}_{3} \mathrm{~N}_{2}$ to temperatures above $560^{\circ} \mathrm{C}$ under $\mathrm{N}_{2}$, followed by hydriding from the gas phase at $250^{\circ} \mathrm{C}$.

An alternative proposal by Luo et al., ${ }^{11}$ involving the same reactants, is based on ball milling $\mathrm{LiNH}_{2}$ and $\mathrm{MgH}_{2}$

$$
\begin{aligned}
2 \mathrm{LiNH}_{2}+\mathrm{MgH}_{2} & \rightarrow \mathrm{Mg}\left(\mathrm{NH}_{2}\right)_{2}+2 \mathrm{LiH} \\
\leftrightarrow & \mathrm{Li}_{2} \mathrm{MgN}_{2} \mathrm{H}_{2}^{\prime}+2 \mathrm{H}_{2}
\end{aligned}
$$

where ' $\mathrm{Li}_{2} \mathrm{MgN}_{2} \mathrm{H}_{2}$ ' is claimed to be single phase and apparently a new compound. The measured reversible hydrogen capacity of this reaction was 5 mass $\%$ at temperatures around $200^{\circ} \mathrm{C}$ and pressures of $20-60$ bar.

In parallel with these developments, interest in the rather intractable compound $\mathrm{LiBH}_{4}$ has been reawakened by Züttel et al. ${ }^{12,13} \mathrm{LiBH}_{4}$ melts at $\sim 275^{\circ} \mathrm{C}$ and decomposes at higher temperatures, starting at $\sim 350^{\circ} \mathrm{C}$, but principally above $\sim 450^{\circ} \mathrm{C}$, according to

$$
\mathrm{LiBH}_{4} \rightarrow \mathrm{LiH}+\mathrm{B}+1 \cdot 5 \mathrm{H}_{2}
$$

Again, LiH is apparently stable in this reaction and $\frac{3}{4}$ of the 18.5 mass $\%$ of hydrogen in the borohydride, i.e. 13.8 mass $\%$, was released.

The dissociation reaction was catalysed when $\mathrm{LiBH}_{4}$ was mixed with $\mathrm{SiO}_{2}$ in the approximate molar ratio $1: 1$, with most of the hydrogen released at temperatures below $\sim 400^{\circ} \mathrm{C}$, compared with $>500^{\circ} \mathrm{C}$ when uncatalysed. A claim ${ }^{14}$ that the reverse reaction occurs at $690^{\circ} \mathrm{C}$ under 200 bar $\mathrm{H}_{2}$ pressure is yet to be verified.

Two very promising approaches to accessing the $\mathrm{H}$ atoms in $\mathrm{LiBH}_{4}$ involve mixing the borohydride with less stable hydrides. Pinkerton et al. $^{15}$ claim to have produced a new compound by ball milling or by simply heating the mixed borohydride and amide to $\sim 100^{\circ} \mathrm{C}$ with equivalent results

$$
\mathrm{LiBH}_{4}+2 \mathrm{LiNH}_{2} \rightarrow \mathrm{Li}_{3} \mathrm{BN}_{2} \mathrm{H}_{8}
$$

This compound melts at $\sim 190^{\circ} \mathrm{C}$ and liberates $>10$ mass $\%$ hydrogen above $250^{\circ} \mathrm{C}$. The products are, in addition to hydrogen, predominantly $\mathrm{Li}_{3} \mathrm{BN}_{2}$ but with some release of ammonia. Attempts to reverse the reaction have not so far succeeded.

Vajo et al. ${ }^{16}$ milled together $\mathrm{LiBH}_{4}$ and $\mathrm{MgH}_{2}$, with 2-3 $\mathrm{mol}^{-} \% \mathrm{TiCl}_{3}$, the catalyst used with conspicuous success to catalyse the dissociation and recombination of $\mathrm{NaAlH}_{4}{ }^{17}$ and initiating the exploration of non-metallic hydrides

$$
\mathrm{LiBH}_{4}+0 \cdot 5 \mathrm{MgH}_{2} \leftrightarrow \mathrm{LiH}+0 \cdot 5 \mathrm{MgB}_{2}+2 \mathrm{H}_{2}
$$

Again assuming that the $\mathrm{LiH}$ is stable, 11.5 mass $\%$ accessible hydrogen is contained. Under 100 bar $\mathrm{H}_{2}$ pressure, absorption began at $230-250^{\circ} \mathrm{C}$. After several cycles a reversible capacity of $\sim 9 \mathrm{wt} \%$ at $300^{\circ} \mathrm{C}$ was reached.

\section{Conclusions}

The developments surveyed are not the only ones in the race to produce a viable hydrogen storage system, but they are probably the most significant in recent years and are certainly dominating research worldwide into direct (as distinct from 'chemical') hydrogen storage systems. The developments in lithium based materials signify a coming shift in emphasis away from searching for materials which will release more than a few mass $\%$ hydrogen, to improve the other properties of materials that already meet the 2010 or even 2015 density targets: reaction rates, desorption temperature for 1 bar released $\mathrm{H}_{2}$ and the pressure and temperature required for reabsorption of hydrogen. This rapid progress in a very few years shows that the situation for solid state hydrogen storage is hopeful, with materials in view which do release sufficient hydrogen, allowing some confidence that a reversible capacity of 10 mass $\%$ can be achieved by 2015. In contrast, the pressurised gas approach is very unlikely to succeed, taking the DOE targets as the only criteria, constrained as it is by the very high hydrogen pressures required to achieve the target hydrogen densities at room temperature.

\section{References}

1. L. Schlapbach and A. Züttel: Nature, 2001, 414, 353.

2. US Department of Energy: 'Basic research needs for the hydrogen economy', US DOE, Washington, DC, USA, 2004, 32.

3. J. Ko and K. Newell: 'Low cost, high efficiency, high pressure hydrogen storage', DOE Hydrogen Program FY2005 Progress Report, Department of Energy, Washington, DC, USA, 2005, 653.

4. H. Hemmes, A. Driessen and R. Griessen: J. Phys. C, 1986, 19C, 3571

5. K. McLennan and E. MacA. Gray: Meas. Sci. Technol., 2004, 15, 1.

6. L. Zhou: Renew. Sust. Energ. Rev., 2005, 9, 395.

7. P. Chen, Z. Xiong, J. Luo, J. Lin and K. L. Tan: Nature, 2002, 420, 302.

8. T. Ichikawa, N. Hanada, S. Isobe, H. Leng and H. Fujii: $\overline{\text { J. Phys. }}$ Chem. B., 2004, 108B, 7887.

9. J. Larminie and A. Dicks: 'Fuel cells systems explained', 2nd edn; 2003, New York, Wiley.

10. Y. Nakamori, G. Kitahara, K. Miwa, S. Towata and S. Orimo: Appl. Phys. A. 2005, 80A, 1.

11. W. Luo and S. Sickafoose: J. Alloy. Compd, 2006, 407, 274.

12. A. Züttel, P. Wenger, S. Rentsch, P. Sudan, P. Mauron and C. Emmenegger: J. Power Sources, 2003, 118, 1.

13. A. Züttel, S. Rentsch, P. Fischer, P. Wenger, P. Sudan, P. Mauron and C. Emmenegger: J. Alloys Compd, 2003, 356-357, 515.

14. A. Züttel, P. Wenger, P. Sudan, P. Mauron and S. Orimo: Mater. Sci. Eng. B., 2004, B108, 9

15. F. E. Pinkerton, G. P. Meisner, M. S. Meyer, M. P. Balogh and M. D. Kundrat: Phys. Chem. B., 2005, 109B, 6

16. J. J. Vajo, S. L. Skeith and F. Mertens: Phys. Chem. B., 2005, 109B, 3719.

17. B. Bogdanovic and M. Schwickardi: J. Alloys Compd, 1997, 253254, 1 . 